\title{
APLIKASI SISTEM PRESENSI MAHASISWA BERBASIS ANDROID
}

\author{
Nandang Hermanto \\ Program Studi Teknik Informatika \\ STMIK Amikom Purwokerto \\ Email: nandanghermanto@amikompurwokerto.ac.id \\ Nurfaizah \\ Program Studi Sistem Informati \\ STMIK Amikom Purwokerto \\ Email: nurfaizah@amikompurwokerto.ac.id \\ Nur Rahmat Dwi Riyanto \\ Program Studi Teknik Informatika \\ STMIK Amikom Purwokerto \\ Email: nrahmatd@gmail.com
}

\begin{abstract}
ABSTRAK
Salah satu indikator yang dijadikan salah satu penilaian dalam proses perkuliahan adalah rekap kehadiran mahasiswa yang tertuang dalam presensi mahasiswa. Penelitian ini bertujuan membuat rancangan sistem presensi mahasiswa menggunakan sistem operasi android, hal ini didasarkan pada pemanfaatan teknologi komunikasi yang sedang berkembang dengan pesat yaitu penggunaan smart phone dengan menggunakan sistem operasi android. Perancangan sistem presensi yang akan dibuat memanfaatkan teknologi Quick Respone Code yang selanjutnya disebut $Q R$ Code yang nantinya akan digunakan dalam proses presensi, $Q R$ Code merupakan teknologi yang dapat menyampaikan informasi secara cepat dan memperoleh respon secara cepat pula. Rekomendasi pembacaan $Q R$ Code oleh mahasiswa nantinya dapat menggunakan $Q R$ Code Reader. QR Code yang disarankan untuk digunakan sebagai alat untuk memunculkan kode $Q R$ Code yang nantinya akan dibaca oleh Quick Respon Code yang harus sudah terinstal di handphone mahasiswa adalah Generate $Q R$ Code. Penggunakan teknologi tersebut dalam pembuatan presensi diharapkan menjadikan sebuah terobosan baru sebuah smart system dalam proses perkuliahan. Salah satu dasar dibuatnya smart system ini adalah karena seringnya mahasiswa menitip absen pada saat perkulihan, sehingga penilaian presensi untuk dijadikan sebagai salah satu indikator dalam penilaian perkulihan menjadi kurang maksimal. Perancangan proses presensi mahasiswa ini menghasilkan desain $U M L$ yang nantinya dapat dijadikan sebagai dasar pembangunan sistem meliputi desain use case, class diagram, squence diagram. Proses selanjutnya yaitu mengimplementasikan sistem presensi berbasis android dengan menggunakan teknologi $Q R$ Code.
\end{abstract}

Kata kunci: presensi; android; mahasiswa; QR Code.

\begin{abstract}
One of the indicators which becomes one of the assessment in the process of lecturing is the recapitulation of the students' presence in the attendance list. This study aims to make the system design of students' presence using Android operating system. It is based on the use of communication technology which is growing rapidly in the use of smart phone with Android operating system. The system design of students' presence used quick response code technology or QR Code which will be applied in the presence. $Q R$ Code is a technology that can convey information quickly and obtain response sooner. Recommendation of reading $Q R$ code by students will be able to use $Q R$ Code reader. Suggested $Q R$ Code is Generated $Q R$ code which is used as a means to bring up the code which will be read by $Q R$ code and it must be installed first in mobile student. The use of technology in the making of presence is expected to make a breakthrough that is a smart system in the lecturing process. One of the reason why this smart system was made is because the some students told other friends to sign their attendance in class so the assessment of presence which is used as one of indicators in the final assessment cannot be achieved maximally. The design of the students' presence produced the design of UML which can then be used as a basis of development system including the design of use case, class diagram, sequence diagram. Next process is to implement the system of presence Android-based using technology QR code.
\end{abstract}

Keywords: presence; android; student; $Q R$ code. 


\section{PENDAHULUAN}

Teknologi dan telekomunikasi sedang berkembang dengan pesatnya saat ini dan sangat memungkinkan untuk dimanfaatkan sebagai alat untuk mempermudah proses presensi perkuliahan. Salah satunya teknologi $Q R$, merupakan media yang dapat digunakan untuk penyimpanan informasi secara cepat dan mendapat respon yang cepat tanpa melakukan input secara manual dengan cara mengetik. Informasi yang dikodekan dalam $Q R$ Code dapat berupa URL, nomor telepon, pesan SMS, V-Card, atau teks apapun [1]. Selain itu keuggulan penggunaan $Q R$ Code mudah dipindai dan data yang dihasilkan dapat langsung diketahui [2].

Penerapan $Q R$ Code telah diterapkan pada presensi pelatihan dan hasilnya lebih cepat dan efisien [3]. Penggunaan yang lain dari $Q R$ Code diterapkan pada sistem presensi ujian dapat mempermudah dosen dalam proses presensisi ujian dan sistem yang dikembangkan dapat menguji kecurangan mahasiswa dalam mengikuti ujian karena terdapat notifikasi [4]. Implementasi sistem presensi dengan menggunakan $Q R$ Code secara umum dapat menghasilkan informasi presensi yang tepat karena tercantum waktu dan tidak bias berubah, selain itu hasil dari sistem tersebut dapat mengatasi masalah kecurangan dalam proses presensi dilihat dari segi keamanan $Q R$ Code rumit karena data yang tersimpan tidak dapat dilihat hanya dari codenya [5], selain itu Penggunaan $Q R$ Code dapat membantu meningkatkan sistem pembelajaran [6]

Proses presensi yang dilakukan saat ini menggunakan sistem yang lebih dikenal dengan epresensi berbasis website, prosesnya dosen memanggil mahasiswa satu per satu untuk divalidasi kehadiran pada sistem epresensi. Sistem yang berjalan saat ini masih membutuhkan waktu lama untuk proses presensinya. Dalam penelitian ini akan dibuat aplikasi presensi mahasiswa menggunaan $Q R$ Code dengan mengkombinasikan dengan penggunaan International Mobile Station Equipment Indentity (IMEI) sebagai nomor unik dari handphone, hal ini bertujuan agar 1 (satu) mahasiswa hanya memiliki 1 akun yang digunakan untuk presensi. Pemanfaatan $Q R$ Code dan IMEI sebagai alat untuk melakukan presensi dalam penelitian ini diharapkan dapat mempermudah dan mempercepat proses presensi pada saat perkuliahan, serta memberikan kemudahan kepada dosen dalam merekap kehadiran mahasiswa, selain itu juga untuk menghindari kecurangan pada proses presensi seperti titip absen yang selama ini banyak terjadi.

\section{METODOLOGI PENELITIAN}

Konsep penelitian yang digunakan dalam pembuatan aplikasi sistem presensi mahasiswa berbasis android ini adalah metode waterfall yaitu metode klasik bersifat sistematis berurutan dalam membangun software. Menyediakan pendekatan alur hidu perangkat lunak secara sekuensial atau berurutan dimulai dari analisis, desain, pengkodean, pengujian dan tahap pendukung (support) [7]. Metode waterfall yang digunakan dalam penelitian seperti dilihat pada Gambar 1.

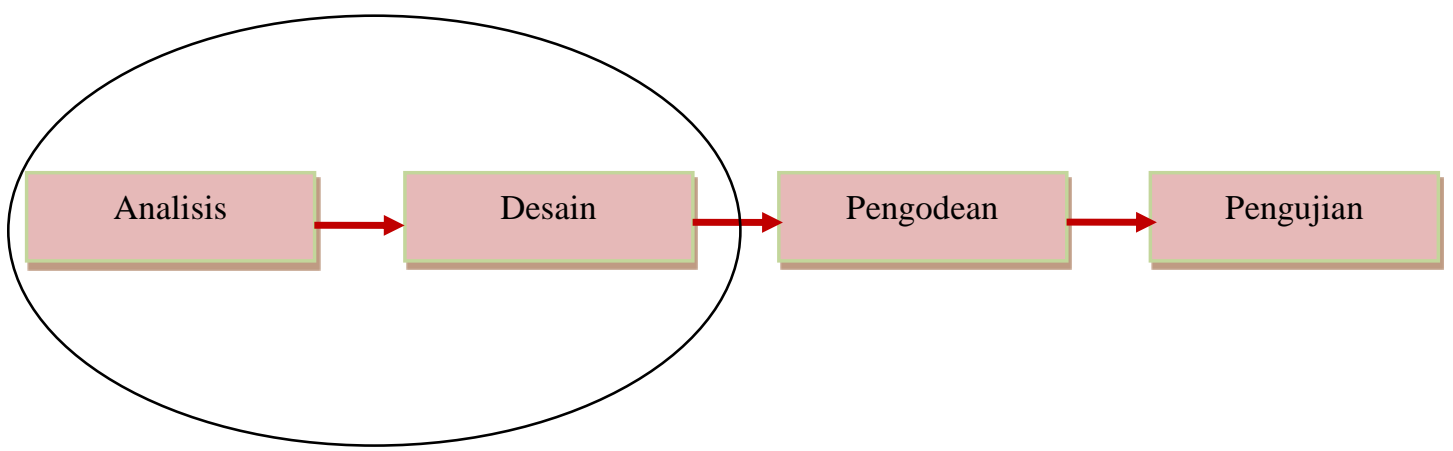

Gambar 1. Diagram Alir Tahapan Penelitian Model Waterfall

Berikut langkah-langkah proses penelitian yang akan dilakukan, pengembangan perangkat lunak dilakukan dengan menggunakan metode waterfall yang terdiri dari:

a) Analisis

Tahap analisis kebutuhan perangkat lunak secara intensif untuk menspesifikasikan kebutuhan sistem agar dapat dipahami sistem seperti apa yang dibutuhkan oleh user.

b) Desain

Tahap desain adalah proses multi langkah yang fokus pada desain pembuatan program sistem termasuk struktur data, arsitektur sistem, representasi antarmuka dan prosedur pengodean.Tahap ini mentranslasi kebutuhan sistem dari tahap analsis kebutuhan ke representasi desain agar dapat diimplementasikan menjadi program pada tahap selanjutnya. 
c) Pengodean

Pada tahap pengodean, desain harus ditranslasikan ke dalam program sistem. Hasil dari tahap ini adalah program komputer sesuai dengan desain yang telah dibuat pada tahap desain.

d) Pengujian

Tahap pengujian fokus pada sistem dari segi logika dan fungsional dan memastikan bahwa semua bagian sudah diuji. Hal ini dilakukan untuk meminimalisir kesalahan (error) dan memastikan keluaran yang dihasilkan sesuai dengan yang diinginkan.

\section{HASIL DAN PEMBAHASAN}

\subsection{Analisis}

Pada tahapan analisis kebutuhan sistem dilakukan beberapa cara untuk mengumpulkan data diantaranya dengan melakukan studi pustaka dan observasi pada saat melakukan presensi mahasiswa. Fokus masalah dalam penelitian ini adalah bagaimana membuat sebauh aplikasi presensi yang dapat memberikan kecepatan dalam proses presensi dengan menerapkan $Q R$ Code yang memanfaatkan teknologi android. Adapun proses bisnis yang diusulkan dalam penelitian ini adalah sebagai berikut:

a) Dosen dan mahasiswa mendaftar ke aplikasi presensi online.

b) Pada saat mahasiswa mendaftar secara otomatis sistem akan IMEI dari HP mahasiswa sehingga, hal ini ditujukan agar satu mahasiswa memiliki satu akun yang tidak dapat dipinjam dan juga digunakan untuk menghindari titip absen.

c) Menu pada mahasiswa terdiri dari gabung ke kelas dan melihat kelas yang diikuti. Menu pada dosen terdiri dari membuat kelas baru, membuat kelas yang diampu.

\subsection{Desain}

Secara detail proses bisnis dan actor yang dalam penelitian ini seperti pada tabel 1 dibawah ini:

Tabel 1. Detail Proses Bisnis

\begin{tabular}{|c|c|c|}
\hline No & Actor & Keterangan \\
\hline 1 & Mahasiswa & $\begin{array}{l}\text { a. Mendaftar ke sistem } \\
\text { b. Gabung ke dalam kelas } \\
\text { c. Melihat kelas yang diikuti } \\
\text { d. Melihat daftar mahasiswa } \\
\text { e. Lakukan presensi } \\
\text { f. Daftar hadir sesi terakhir } \\
\text { g. Daftar tidak hadir sesi terakhir } \\
\text { h. Daftar hadir keseluruhan } \\
\text { i. Rekap kehadiran }\end{array}$ \\
\hline 2 & Dosen & $\begin{array}{l}\text { a. Buat kelas baru } \\
\text { b. Kelas yang saya ampu } \\
\text { c. Melihat daftar mahasiswa } \\
\text { d. Lanjutkan sesi presensi terakhir } \\
\text { e. Buka presensi yang baru } \\
\text { f. Daftar hadir sesi terakhir } \\
\text { g. Daftar tidak hadir sesi terakhir } \\
\text { h. Daftar hadir keseluruhan } \\
\text { i. Rekap kehadiran }\end{array}$ \\
\hline
\end{tabular}

Dari tabel 2 kemudaian proses diturunkan ke rancangan use case, sequence diagram dan class diagram sebagai berikut: 


\subsubsection{Use Case Diagram}

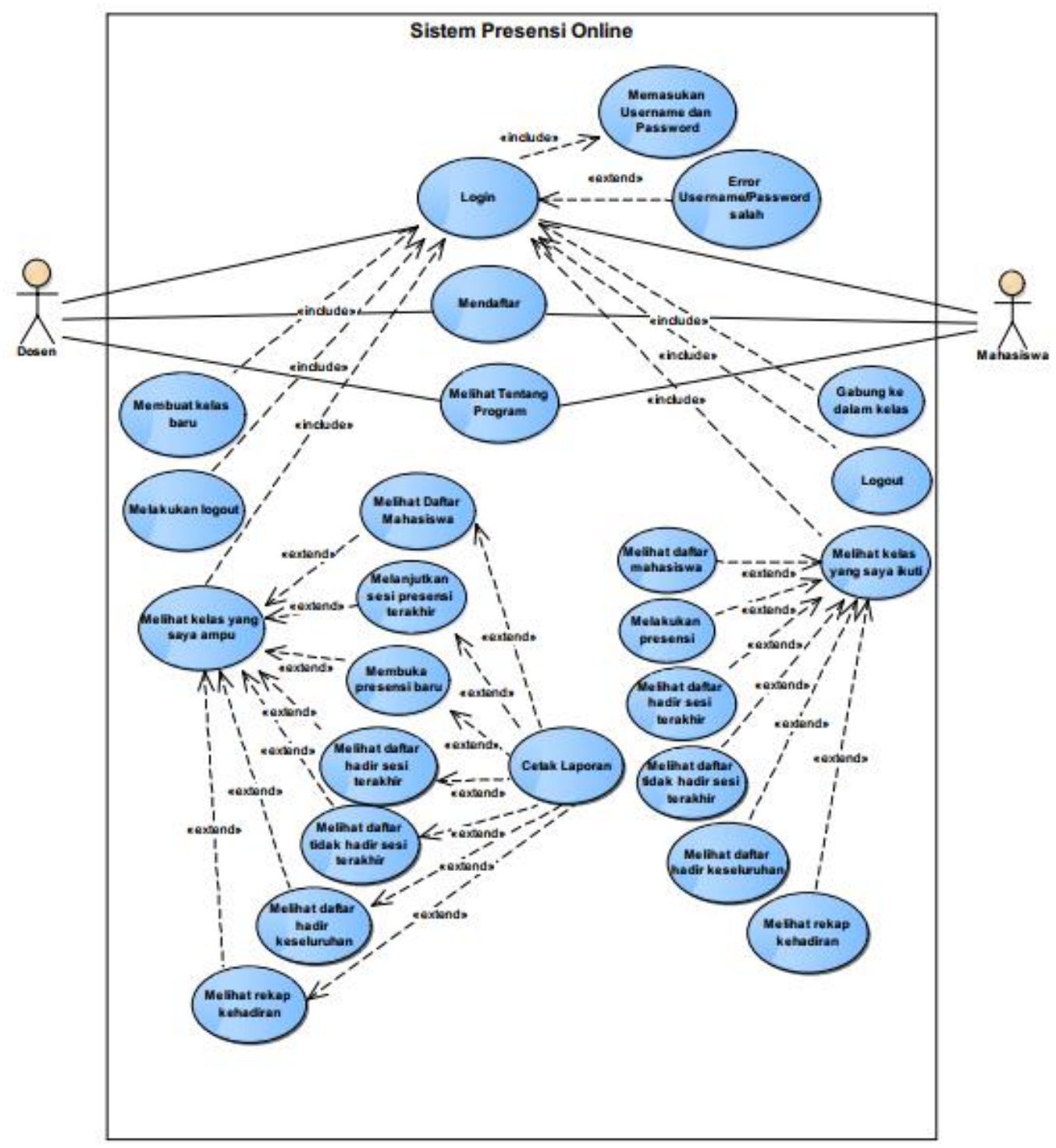

Gambar 2. Use Case Presensi Online

Gambar 2 merupakan desain use case presensi online terdiri dari 2 actor dosen dan mahasiswa. Use case dari actor dosen adalah mendaftar jika belum punya akun jika sudah punya akun lakukan proses login dan muncul menu membuat kelas baru jika baru masuk dalam aplikasi dan ada pilihan kelas yang saya ampu jika sudah membuat kelas baru untuk masing-masing kelas mata kuliah tertentu. Pada menu kelas yang saya ampu dapat melakukan proses untuk melihat daftar mahasiswa, lanjutkan presensi terakhir, buka presensi baru, daftar hadir sesi terakhir, daftar tidak hadir sesi terakhir, daftar hadir keseluruhan, rekap kehadiran.

Actor mahasiswa memiliki use case terdiri dari gabung ke kelas dan kelas yang saya ikuti. Proses actor mahasiswa dapat melihat daftar mahasiswa, lakukan presensi, daftar hadir sesi terakhir, daftar tidak hadir sesi terakhir, daftar hadir keseluruhan dan rekap kehadiran.

\subsubsection{Sequence Diagram Mendaftar Dosen atau Mahasiswa}

Gambar 3 dibawah ini merupakan desain untuk menggambarkan aktifitas dosen maupun mahasiwa untuk melakukan daftar pada aplikasi, ada berberapa aktifitas yang berkaitan dengan aktifitas tersebut seperti mengisi data yang kemudian akan disimpan di database yang selanjutnya akan dijadikan sebagai validasi saat actor melakukan login pada aplikasi. 


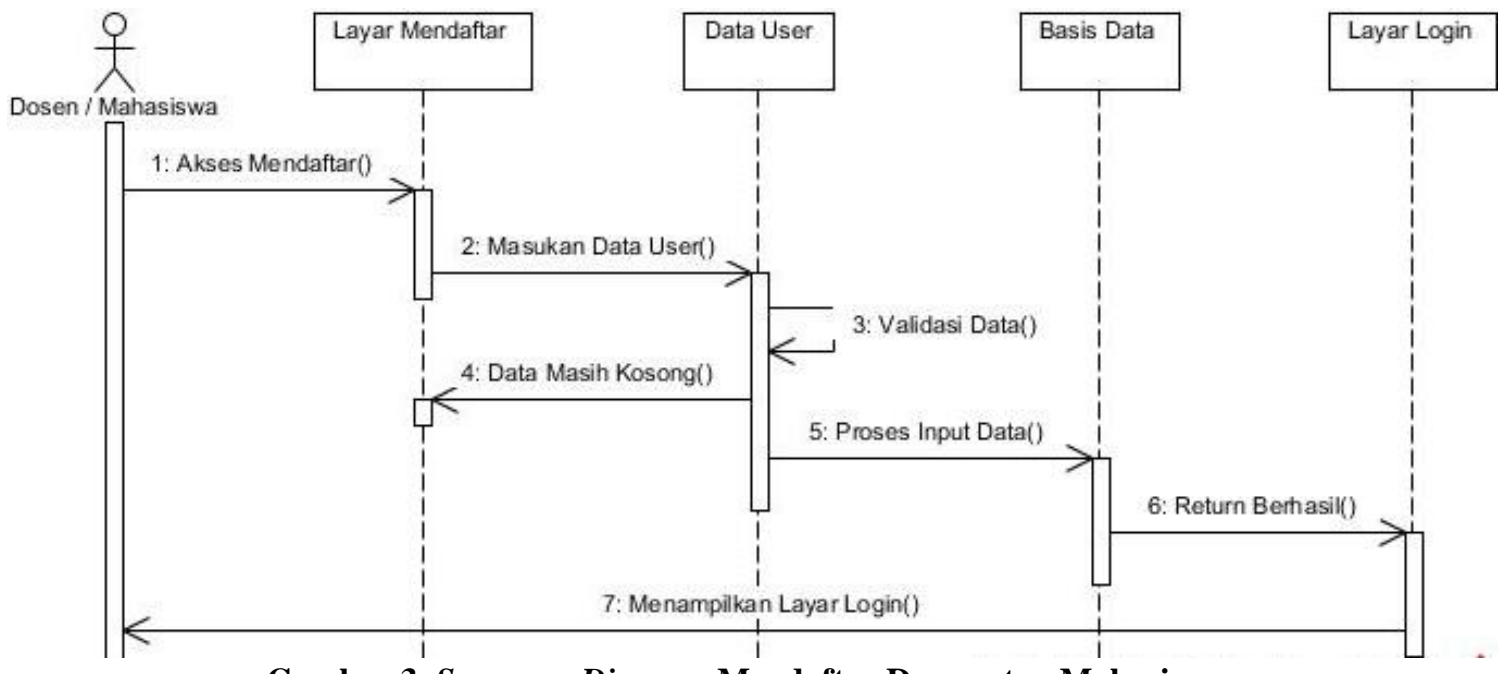

Gambar 3. Sequence Diagram Mendaftar Dosen atau Mahasiswa

\subsubsection{Sequence Diagram Absensi Mahasiswa}

Gambar 4 merupkan gambar acitivas actor dosen untuk mengaktifkan aplikasi presensi online yang dapat diakses oleh mahasiswa.

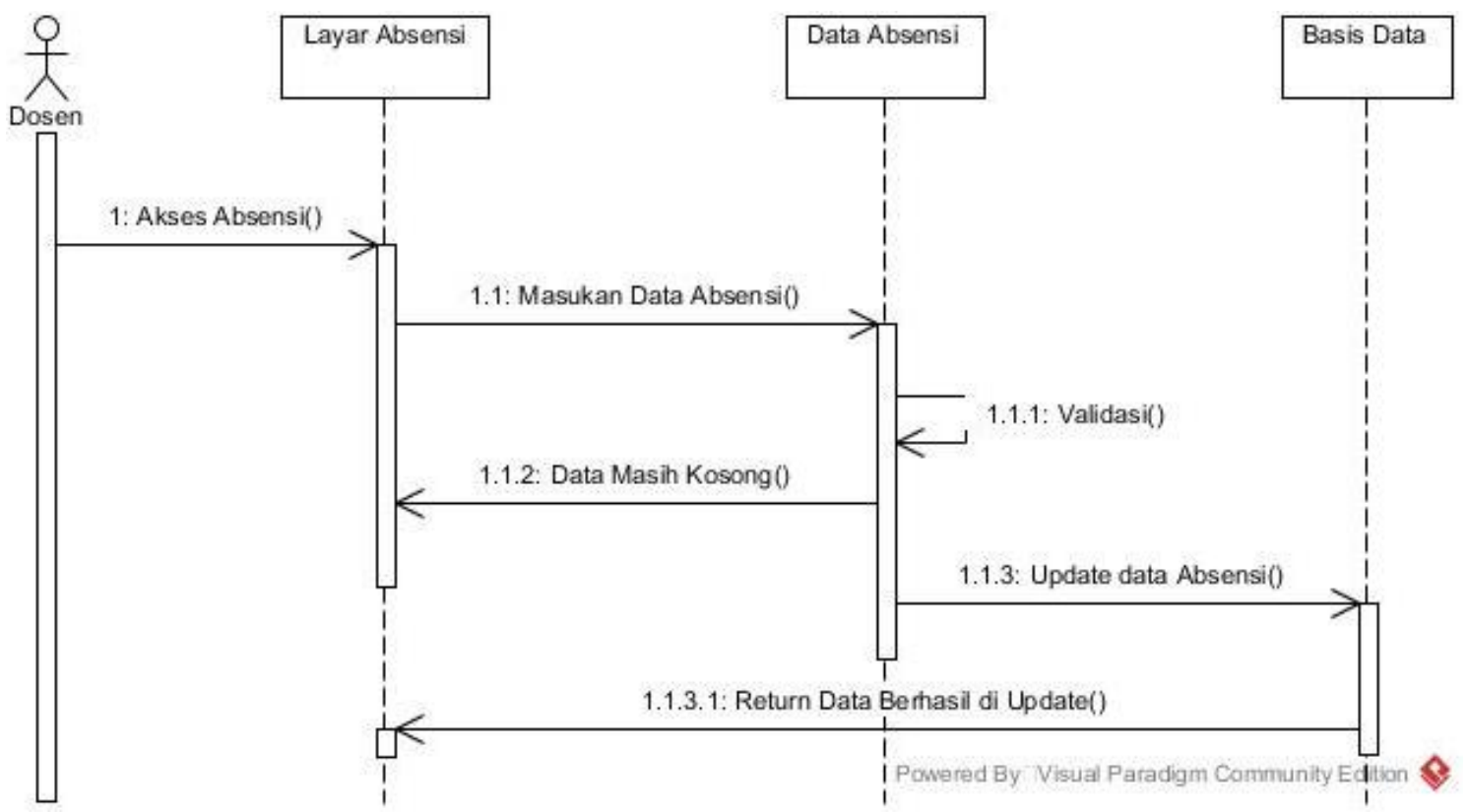

Gambar 4. Sequence Diagram Absensi Mahasiswa 


\subsubsection{Class Diagram}

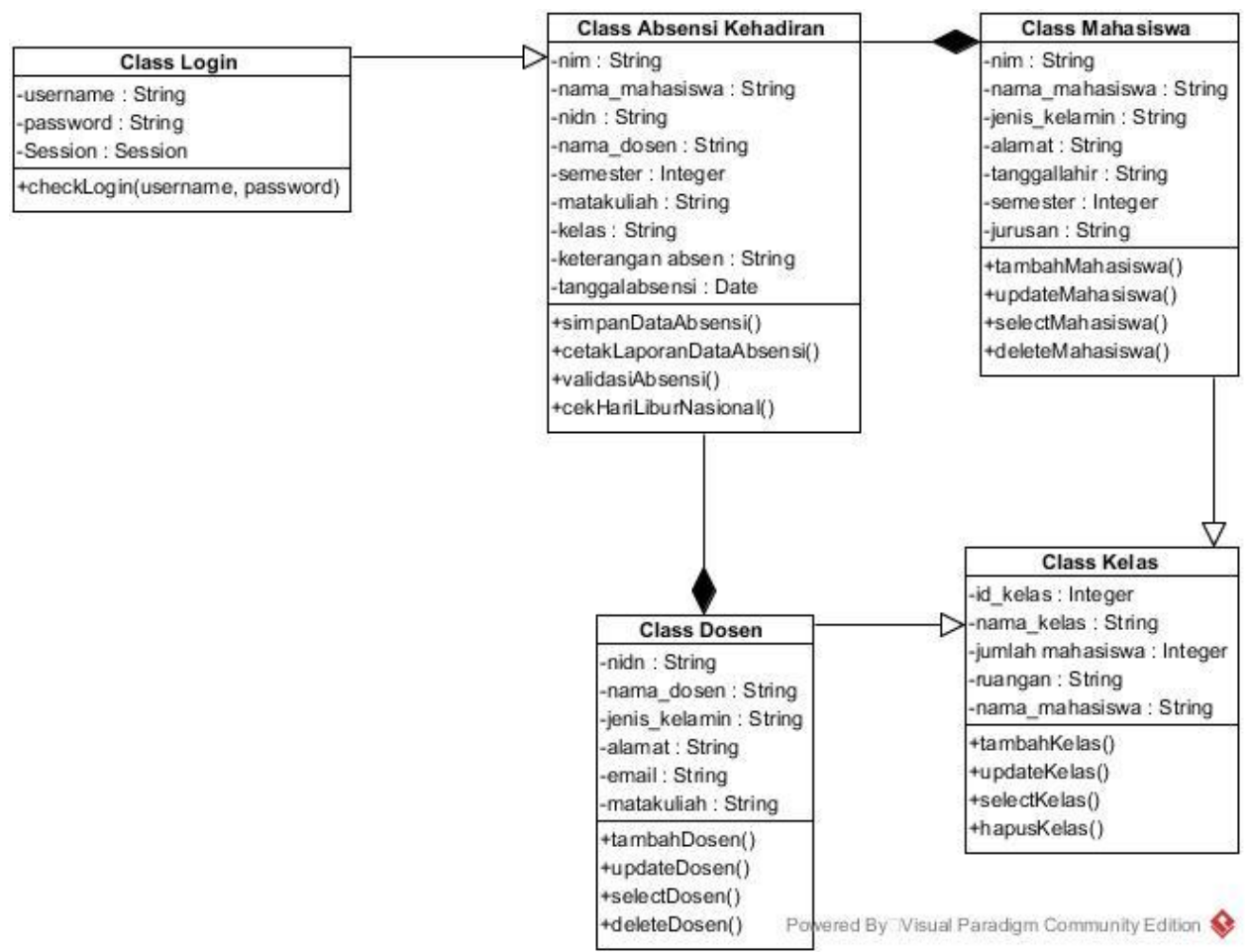

Gambar 5. Class Diagram

Class diagram pada gambar 5 menjelaskan class-class pada kode program dalam aplikasi class absensi kehadiran dapat diakses dengan mengakses terlebih dahulu class diagram. Class absensi kehadiran dipakai oleh class mahasiswa dan class dosen kemudian varibel tersebut dipakai dan diwariskan ke class kelas.

\subsection{Pengkodean}

Tahap pengkodean merupakan tahap merepresentasikan desain sistem ke dalam bahasa program, pada tahap ini juga dilakukan prose implementasi sistem berupa pembuatan antar muka program dan fungsinya didalam sistem presensi mahasiswa. Gambar 6 dibawah ini merupkan sebagain source code proses presensi dari proses pengimplementasian desain ke dalam sistem.

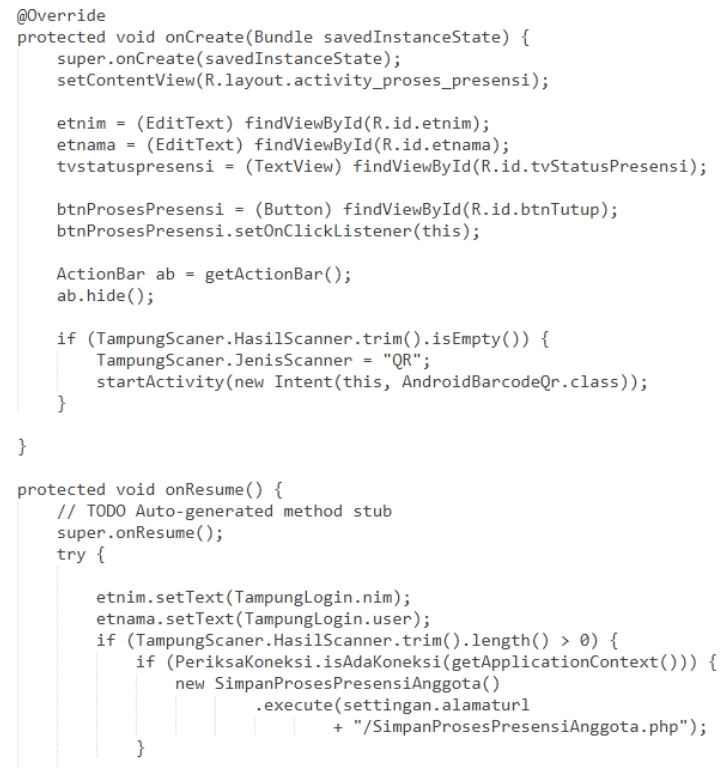

Gambar 6. Source Code Proses Presensi 


\subsection{Aplikasi}

a) Activity Proses Buka Sesi Presensi Baru

Gambar 7 merupakan activity yang memiliki fungsi yang sama dengan activity Lanjutkan Sesi Presensi Terakhir, perbedaanya adalah nomor pertemuan akan bertambah satu dari nomor pertemuan sebelumnya.

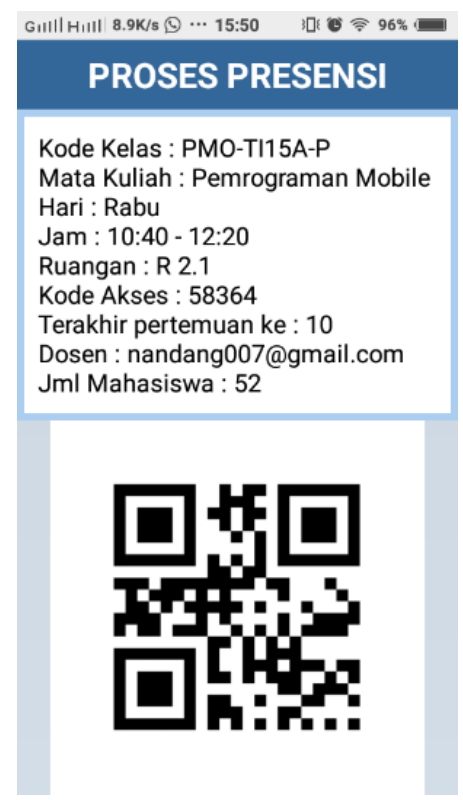

Gambar 7. Activity Proses Buka Sesi Presensi Baru

b) Halaman Proses Presensi

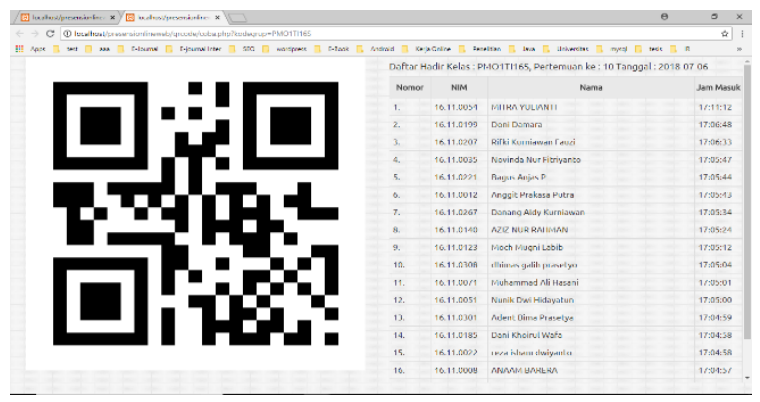

Gambar 8. Halaman Proses Presensi Pada Web

Gambar 8 merupakan halaman yang akan ditampilkan jike memilih menu lanjurkan sesi presensi terakhir atau memilih menu buka sesi presensi baru, perbedaanya adalah jika memilih lanjurkan sesi presensi terakhir maka nomor pertemuan tidak berubah sedangkan jika memilih buka sesi presensi baru maka nomor pertemuan akan bertamah 1 dari sesi sebelumnya. Gambar 9 merupkan implementasi penggunaan sistem di kelas.

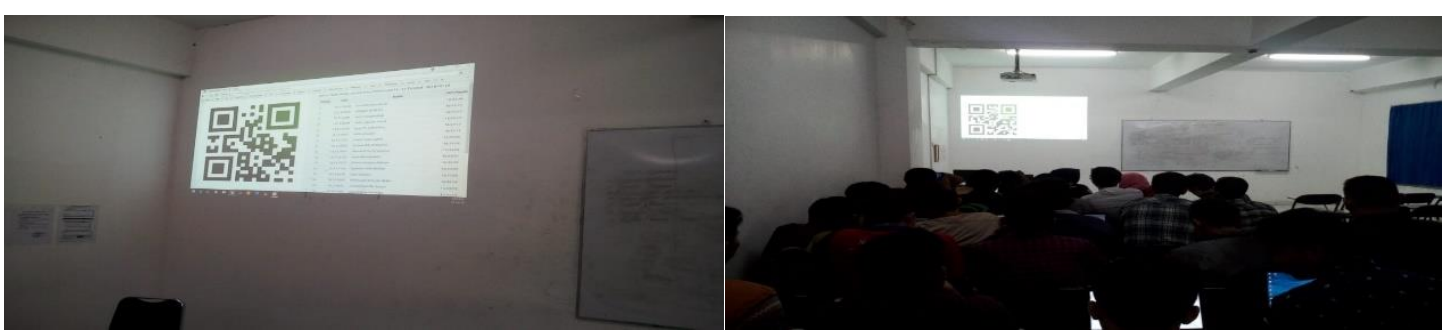

Gambar 9. Proses Penggunaan Sistem Presensi Berbasis Android Di Kelas 
c) Rekap Kehadiran Mahasiswa Setiap Selesai Perkuliahan

\begin{tabular}{|c|c|c|c|c|}
\hline \multicolumn{5}{|c|}{$\begin{array}{l}\text { DAFTAR HADIR SESI KE } 10 \\
\text { Kelas :Pemrograman Mobile } 1\end{array}$} \\
\hline No. Urut & NIM & Nama & Tanggal & Jam \\
\hline 1 & 16.11.0008 & ANAAM BARERA & $2018-06-05$ & 17:04:57 \\
\hline 2 & 16.11.0012 & Anggit Prakasa Putra & $2018-06-05$ & $17: 05: 43$ \\
\hline 3 & 16.11 .0022 & reza isham dwiyanto & $2018-06-05$ & $17: 04: 58$ \\
\hline 4 & 16.11 .0028 & Grisela Diki Ardiyanto & $2018-06-05$ & 17:04:56 \\
\hline 5 & 16.11 .0035 & Novinda Nur Fitriyanto & $2018-06-05$ & 17:05:47 \\
\hline 6 & 16.11.0051 & Nunik Dwi Hidayatun & $2018-06-05$ & 17:05:00 \\
\hline 7 & 16.11 .0054 & MITRA YULIANTI & $2018-06-05$ & 17:11:12 \\
\hline 8 & 16.11.0071 & Muhammad Ali Hasani & $2018-06-05$ & 17:05:01 \\
\hline 9 & 16.11.0123 & Moch Mugni Labib & $2018-06-05$ & 17:05:12 \\
\hline 10 & 16.11.0140 & AZIZ NUR RAHMAN & $2018-06-05$ & 17:05:24 \\
\hline 11 & 16.11 .0185 & Dani Khoirul Wafa & $2018-06-05$ & $17: 04: 58$ \\
\hline 12 & 16.11.0199 & Doni Damara & $2018-06-05$ & $17: 06: 48$ \\
\hline 13 & 16.11.0207 & Rifki Kurniawan Fauzi & $2018-06-05$ & 17:06:33 \\
\hline 14 & 16.11.0221 & Bagus Anjas P & $2018-06-05$ & 17:05:44 \\
\hline 15 & 16.11.0248 & Esa Rizki Anandrian & $2018-06-05$ & $17: 04: 55$ \\
\hline 16 & 16.11.026? & Danang Aldy Kurniawan & $2018-06-05$ & $17: 05: 34$ \\
\hline 17 & 16.11.0301 & Adent Bima Prasetya & $2018-06-05$ & 17:04:59 \\
\hline 18 & 16.11.0308 & dhimas galih prasetyo & $2018-06-05$ & 17:05:04 \\
\hline
\end{tabular}

Gambar 10. Rekap Kehadiran Mahasiswa Setiap Selesai Perkuliahan

Gambar 4.46 adalah halaman ini berisi daftar hadir mahasiswa pada sesi terakhir, dilengkapi dengan jam mahasiswa tersebut melakukan presensi.

d) Rekap Kehadiran Mahasiswa Selama Satu (1) Semester

\begin{tabular}{|c|c|c|c|c|c|}
\hline \multicolumn{6}{|c|}{$\begin{array}{l}\text { DAFTAR HADIR KESELURUHAN } \\
\text { Kelas :Pemrograman Mobile } 1\end{array}$} \\
\hline No. Urut & NIM & Nama & Tanggal & $\mathrm{Jam}$ & SESI \\
\hline 1 & 16.11 .0001 & Fahmi Yahya & $2018-04-10$ & $16: 47: 25$ & \\
\hline 2 & 16.11 .0001 & Fahmi Yahya & 2018-04-10 & 18:28:29 & 2 \\
\hline 3 & 16.11 .0001 & Fahmi Yahya & 2018-04-17 & 16:44:14 & 3 \\
\hline 4 & 16.11 .0001 & Fahmi Yahya & 2018-04-17 & 18:29:38 & 4 \\
\hline 5 & 16.11 .0001 & Fahmi Yahya & 2018-04-24 & $16: 45: 03$ & 5 \\
\hline 6 & 16.11 .0001 & Fahmi Yahya & 2018-04-24 & 18:32:46 & 6 \\
\hline 7 & 16.11.0001 & Fahmi Yahya & $2018-05-15$ & $18: 36: 34$ & 8 \\
\hline 8 & 16.11.0007 & wasis budiprayitno & 2018-04-18 & 15:46:59 & 3 \\
\hline 9 & 16.11.0007 & wasis budiprayitno & 2018-04-18 & 15:48:21 & 4 \\
\hline 10 & 16.11.0007 & wasis budiprayitno & 2018-04-24 & $16: 45: 52$ & 5 \\
\hline 11 & 16.11.0007 & wasis budiprayitno & $2018-04-24$ & 18:38:34 & 6 \\
\hline 12 & 16.11 .0007 & wasis budiprayitno & 2018-05-15 & $17: 17: 12$ & 7 \\
\hline 13 & 16.11.0007 & wasis budiprayitno & 2018-05-15 & $18: 36: 58$ & 8 \\
\hline 14 & 16.11 .0008 & ANAAM BARERA & 2018-04-10 & 16:47:23 & 1 \\
\hline 15 & 16.11 .0008 & ANAAM BARERA & 2018-04-10 & 18:28:32 & 2 \\
\hline 16 & 16.11 .0008 & ANAAM BARERA & 2018-04-17 & 16:44:01 & 3 \\
\hline 17 & 16.11 .0008 & ANAAM BARERA & 2018-04-17 & 18:30:01 & 4 \\
\hline 18 & 16.11.0008 & ANAAM BARERA & 2018-04-24 & $16: 44: 51$ & 5 \\
\hline 19 & 16.11 .0008 & ANAAM BARERA & 2018-04-24 & 18:32:18 & 6 \\
\hline 20 & 16.11 .0008 & ANAAM BARERA & $2018-05-15$ & 17:15:25 & 7 \\
\hline 21 & 16.11 .0008 & ANAAM BARERA & $2018-05-15$ & 18:36:11 & 8 \\
\hline 22 & 16.11 .0008 & ANAAM BARERA & 2018-06-05 & $16: 46: 17$ & 9 \\
\hline 23 & 16.11.0008 & ANAAM BARERA & 2018-06-05 & 17:04:57 & 10 \\
\hline
\end{tabular}

Gambar 11. Rekap Kehadiran Mahasiswa Selama Satu (1) Semester

Halaman ini berisi rincian daftar hadir masing masing mahasiswa dari sesi pertama sampai sesi terakhir seperti pada gambar 11.

\subsection{Pengujian}

Setelah melalui tahap pembuatan sistem presensi kemudian masuk ke langkah pengujian sistem,tujuannya untuk melihat apakah sistem yang dibuat sudah berfungsi sesuai dengan yang diharapkan atau belum. Tabel 2 dibawah ini merupakan hasil pengujian sistem. 
Tabel 2. Hasil pengujian sistem

\begin{tabular}{|c|c|c|c|}
\hline No & Daftar Uji & Hasil yang diujikan & Hasil Uji \\
\hline 1 & $\begin{array}{l}\text { Proses masukan } \\
\text { username dan } \\
\text { password }\end{array}$ & $\begin{array}{l}\text { Data login yang benar dapat } \\
\text { masuk ke dalam sistem. Login } \\
\text { Admin masuk ke hak akses } \\
\text { Admin } \\
\text { Data Login salah terdapat } \\
\text { peringatan dan tidak dapat } \\
\text { masuk kedalam sistem }\end{array}$ & Berhasil \\
\hline 2 & $\begin{array}{l}\text { Simpan data } \\
\text { pendaftaran }\end{array}$ & $\begin{array}{l}\text { Pengisian data pendaftaran } \\
\text { lengkap dapat di simpan sesuai } \\
\text { dengan pilihan dosen atau } \\
\text { mahasiswa }\end{array}$ & Berhasil \\
\hline 2 & $\begin{array}{l}\text { Simpan data buat } \\
\text { kelas baru }\end{array}$ & $\begin{array}{l}\text { Pengisian data buat kelas baru } \\
\text { dapat di simpan }\end{array}$ & Berhasil \\
\hline 3 & $\begin{array}{l}\text { Batal buat kelas } \\
\text { baru }\end{array}$ & $\begin{array}{l}\text { Form akan kembali ke default } \\
\text { awal jika klick tombol batal }\end{array}$ & Berhasil \\
\hline 4 & $\begin{array}{l}\text { Menampilkan } \\
\text { daftar kelas yang } \\
\text { di ampu }\end{array}$ & $\begin{array}{l}\text { Form dapat menampilkan } \\
\text { daftar kelas yang diampu berisi } \\
\text { detail data mata kuliah }\end{array}$ & Berhasil \\
\hline 5 & $\begin{array}{l}\text { Menampilkan } \\
\text { daftar mahasiswa } \\
\text { yang diampu }\end{array}$ & $\begin{array}{l}\text { Form dapat menampilkan } \\
\text { daftar mahasiswa yang diampu }\end{array}$ & Berhasil \\
\hline 6 & $\begin{array}{l}\text { Menampilkan } \\
\text { daftar hadir sesi } \\
\text { terakhir }\end{array}$ & $\begin{array}{l}\text { Form dapat menampilkan } \\
\text { daftar hadir sesi terakhir }\end{array}$ & Berhasil \\
\hline 7 & $\begin{array}{l}\text { Menampilkan } \\
\text { rekap kehadiran } \\
\text { seluruh } \\
\text { mahasiswa }\end{array}$ & $\begin{array}{l}\text { Form dapat menampilkan } \\
\text { rekap kehadiran seluruh } \\
\text { mahasiswa }\end{array}$ & Berhasil \\
\hline
\end{tabular}

\section{KESIMPULAN}

Berdasarkan hasil uji coba fungsi aplikasi telah berjalan sesuai yang diharapakn dan implementasi aplikasi sistem presensi mahasiswa berbasis android telah berhasil dibuat dengan menggunakan $Q R$ Code sebagai alat untuk merekam data dapat merekam data kehadiran mahasiswa secara cepat dan dosen dapat mengetahui rekap kehadiran mahasiswa setiap selesai perkuliahan dan sistem juga memberikan rekap kehadiran mahasiswa secara keseluruhan. Aplikasi ini juga telah diimplementasikan dalam perkuliahan dan membantu dosen dalam proses presensi dan rekap kehadiran mahasiswa yang nantinya akan dijadikan salah satu indikator penilaian dalam proses perkuliahan.

Penelitian ini dapat dikembangkan lagi agar dapat menangani permasalahan jika pengguna akan mengganti hanphone yang digunakan untuk mengakases sistem presensi online.

\section{UCAPAN TERIMA KASIH}

Ucapan terima kasih kepada Kementerian Riset, Teknologi, dan Pendidikan Tinggi atas pendanaan penelitian yang kami lakukan.

\section{DAFTAR PUSTAKA}

[1] Denso ADC, “Qr code essentials,” Denso Adc, pp. 1-12, 2011.

[2] I. T. Asare, W. Yan, A. Road, and D. Asare, "The Effective Use of Quick Response ( QR ) Code as a Marketing Tool," vol. 2, no. 12, 2015.

[3] A. R. Safitri and L. A. Sholikhan, "Penggunaan qr code dalam presensi berbasis android," pp. 6-7, 2016.

[4] L. A. Muharom, "SMART PRESENSI MENGGUNAKAN QR-,” no. 2, pp. 31-44, 2016.

[5] M. T. Nuddin and D. L. Fithri, "Sistem Absensi Asisten Dosen Menggunakan Qr Code Scanner Berbasis Android Pada Program Studi Sistem Informasi Universitas Muria Kudus," Pros. SNATIF, vol. 0, no. 0, pp. 303-310, 2015. 
[6] Q. Aini, Y. I. Graha, and S. R. Zuliana, "Penerapan Absensi QRCode Mahasiswa Bimbingan Belajar pada Website berbasis YII Framework Application Student Attendance QRCode in Guidance Learn to Website Based on Yii Framework," vol. 7, no. 2, pp. 207-218.

[7] Rosa, A.S dan Shalahuddin M. 2013. Rekayasa Perangkat Lunak Terstruktur dan Berbasis Objek. Bandung:Informatika 